\title{
Research on Space Design Art in the Subway Station of Regional-Cultural Characteristics
}

\author{
Wenya $\mathrm{Li}^{1,}$ a \\ ${ }^{1}$ Jiyuan Vocational and Technical College, Jiyuan, Henan, China, 454650 \\ aemail,
}

Keywords: Space Design Art, Subway Station, Regional-Cultural Characteristics

\begin{abstract}
With the rapid development of subway, subway station space design artistry abroad more attention, its diversified development trend. But the domestic status of the space station subway art still can not get rid of the traditional image of public space, they did not form their own style and system. Blindly copying foreign subway station space design, lack of local specialties. Subway station with regional cultural space research design is a dynamic design pattern is a leap one design ideas.
\end{abstract}

\section{Introduction}

There are regional cultural, geographic attributes of ancient culture has been the attention and emphasis. "Book of Songs" Fifteen wind reflect the different regions, ideas, styles customs, "Han • Geography" is more clearly reveal a profound impact on the natural environment and shaping of human existence and cultural patterns. Thus, given the basic geographical and cultural background, the initial accumulation of cultural formation. Distribution and geographical differences cultural geography of this objective reality, it provides the backdrop for Broad reaching geographical and cultural studies.

Metro station rooted in the fertile soil of the different regional culture, showing a mix of changes, like the Book of gossip Ai changed, the person, because, because, the result of geographical, astronomical and because there are different forms. Regional Culture includes not only the region around the unique natural and geographical conditions, but also includes the social development process in the region, people formed a unique lifestyle, behavioral customs, mode of thinking, values and so on. It is deeply engraved in people's ideology among.

Unprecedented prosperity in the market today, a large number of foreign designers to participate, local new force is not enough to compete with them. At present, China is facing a new round of Architects imbalance of power or unfair competition. Thriving construction market in the design competition, a broad perspective, the competition of science and technology and economic strength, but also the competition of regional culture. Chinese architects should be familiar with the local culture, to be able to win the competition in this regard, but in fact is not necessarily so. Look around today, "European Wind" rise buildings everywhere, regardless of race conditions, please "foreign" Architect to the local brand name, even worse. All these phenomena reflect our lack of confidence on the Chinese Architecture Culture.

In the present era background, the proposed space station subway art design concept with regional culture is very necessary. "Only the nation, is the world '; only rooted in the local culture, fertile soil, underground space it might have." This is different from another, "the unique features; only with distinct regional characteristics, metro space vitality.

\section{The Concept of Regional Culture}

Culture is territorial, urban growth in China in particular areas, or in different geographical and cultural nurtured among. More and more archaeological excavations prove a long history of Chinese culture is actually a variety of tribal mosaic, also called mosaic "sub-culture", such as the Hemudu culture, Longshan culture, Erlitou culture, regional culture is different people living in a particular geographical environment and history, generations work management, creation, evolution 
results. Side soil support people, nurtured and formed a unique regional culture; distinctive regional culture interacting with each other and influence each other, a common combination of a colorful Chinese cultural space kaleidoscopic picture.

However, the definition of regional culture is not consistent with its relatively obscure extension need to be explored. Taken together, the so-called regional culture should be under certain geographical conditions, such as ocean, such as mountains, rivers, and the climate as well as the unique human spirit and so on, or all of, or produced for cross-cultural (local or foreign) unique, or rather solid, or exclusion, or the integration and increase of its own color, gradually formed its own development and culture Features. So it is no longer the concept of culture in the traditional sense, it is no longer specific to the level of a substance under the economic conditions, but directly subject to geographical restrictions (and already have the human spirit) under, and through various forms the symptom culture. Of course, it is also a reaction to the material aspects of this column.

\section{Research on Space Design Art in the Subway Station of Regional-Cultural Characteristics}

The concept of regional culture is very extensive, specifically it refers to a region's natural environment and cultural and historical synthesis. Research on cultural issues in the metro area of art and design in the field of space, can be divided into three geographical and cultural dimensions of major aspects of the natural environment, human environment, social environment. The natural environment, including climate, topography, hydrology, plant resources, building materials, and other local decorative style; certain levels, including the human environment history traditions, customs, ideas, customs, construction technology. Performance of architectural style, layout space in the subway station space art design. Social environmental dimensions, including economic development and social organization system and other specific areas within the environment, these factors subway station empty 'development between art and design, reflecting the social value of the metro space.

Adapt to the Natural Environment Dimension. Climate largely determines the way of life and range. Important reasons therefore, differences in climate is the formation regions around difference, due to the local nature adapted to the conditions, from temperature, humidity, lighting and other considerations, different architectural image of perennial accumulation produced is on the natural environment of the most obvious manifestation . Natural features and social characteristics of different regions caused by climate is very obvious, different latitude and longitude, altitude, sunshine intensity, vegetation conditions reflected the climate vary widely. These different geographical regions of these people created a climate different behavior, reflected in different people's eating habits, clothing, dress, customs and other aspects. Differences between different regions, the impact to the subway station design.

Varied terrain, many types, there are mountains, plateaus, hills, basins, plains, desert, desert caves. China Plain less mountainous, land height difference. Due to the different altitudes, plus a series of climate and other factors contribute to the ups and downs, Luan Qiu gully, Hustle aspect of rich landscape. These terrain or gentle or steep, or mountain or the endless rolling. People living in these different topography also formed a unique way of life and transportation. .

Facts have proved that the use of local building materials environmental art design has a strong personality and economy. At the subway station space art design, naturally think with local materials, to create a regional, personality, charm economic space. These different regions, different types of materials, you can make the same type of performance at the space environment very different forms and characteristics

Reflects the Human Environment Level. Any city has its emergence and development of historical change, the historical background is the geographical context, it has a unique value, geographical changes in basic research and development update creation. Each piece of land on the planet has formed the historical evolution of mining history cautious, refining history and culture of the region, is the basis for the design work. At the subway station art design process, combined with the site of the historical background, the overall framework of art and design, the idea of combining 
the principles and regional history, maintaining a geographical historical continuity, so that the space station subway art design will have its own unique vitality.

Another important factor is the regional customs, the use of human-oriented design techniques to better express love and respect for nature real life. Underground space has been taken to reflect the customs of the city's quality of positive factors, they not only contribute to the personality, local, historical continuity of the formation of the city, but also on the psychological and urban city life integration role. A local customs and environmental protection has been improved will produce a ripple effect, will lead a stable social environment quality neighborhoods, improve our health and thus promote the development of the city.

The concept of regional culture custom is precious intangible heritage representative. Custom concept is the concept of daily life and behavior most closely connected to one of the basic factors in people's culture, it is the most direct reflection of the human environment of the region. A region passed along from generation to generation, continuous and stable behavior and attitudes formed the concept of custom of the place, which in turn affects people's lives now.

In Line with the Social Environment Level. Social environmental dimensions, including economic development and social organization system. Economic factors are another constraint Subway Station Art Design. Subway operating company is another object designer must be responsible for the subway operator in terms of: the creation of the subway management resources, reduce construction and operation costs, improve operational operating income to achieve economies of subway construction is one of its main goals, so interior designers must consider all possible ways to meet their needs.

\section{Application Principles of the Regional Cultural in the Metro Space Art Design}

In People-Oriented Principle. Metro station space art design is not just to meet the basic functional requirements of traffic, but also includes physical, mental, spiritual and other needs. You can create a good traffic space for users to provide quality services, from the user's physiological, behavioral requirements as a basis, taking into account the requirements of different groups of people, to provide convenience. In principle people can text the following aspects reflect: (1) provide a comfortable physical environment: Metro Station space design in addition to effective rain, wind and airflow outside, physical comfort also includes effective sun protection or introduced, and maintain proper lighting conditions are factors that must be considered; the same time, people in the subway space environment hearing and smell the environment should be considered. (2) create a comfortable psychological environment: comfortable not only in the physical, psychological comfort but also must pay attention to. "People-oriented" is not only designed to be considerate, consider the user's habits and physiological requirements, but also reflected at the user's spiritual care.

Prominent Local Personality Principles. Modern city Every city has its own personality and characteristics, in addition to natural factors such as geographical characteristic formation of the city, along with the research and development of urban design discipline, so that the city given new meaning. Metro station space art design should highlight the city's image of the city's own characteristics, each city has its own different historical backgrounds, different terrain and climate, urban residents have different ideas, different habits, "side soil support people "proverb clever location name for the environmental impact of people, can say that it gave birth to the complex environment of different posture, utterly human character, subway station design should fully reflect the personality of this city.

Inheritance and Innovation Principles. History is a need to inherit not only help local personalities, local, historical continuity of the formation, but also on the psychological development of urban residents and the city's motivational. Forming a subway station both its practical significance, but also bear its profound historical connotation, except for a few zone or "artificial city" does not have some of the natural environment or historical significance than generally is inseparable from its traditional organized spatial form, shaping the city's unique personality, those with historical, traditional space architectural forms, colors, materials, symbols, 
and lifestyle and so on, and just hide all citizens of the new, local produce and control their behavior social values and cultural identity coincide, it is easy to arouse public sympathy, to arouse public memories of the past, produce cultural identity.

Holistic Principles. (Hol1sticdesign) is an important design ideas of modern urban design, a concept linked to things or to solve real problems, it is also better reflect the subway station in space design. For the metro station, the "overall design" should be thought through the whole process of underground space design. Metro Station Space Art design requirements of the elements constituting the group environment this situation, take care of each other, highlighting the overall characteristics.

Principles Of Sustainable Development. Each one subway construction urban planning not only one line, each line construction and operation are not isolated, it is line with the future of the different parts of the same system. Now do a line of artistic space station design must take into consideration, we can not wait for the new line built, found to be harmonized with the old line art and design space, or conflict. Such as logo colors geo-positioning yellow line 1, it is necessary to strengthen the appropriate color change is reflected, not just a lot of key positions on the use of color, or in the future after the completion of the new line station is easy to produce with color confusion.

\section{Conclusions}

With the construction of the subway, people turned to the subway station design, depending on the metro station is building slowly into their art space. However, only art into the space station is not enough, something very dull monotony of building space has a local subway station Arts Culture imminent. Different regions have different cultures, different cultures bring different aesthetic taste, lifestyle. Art Space Research subway station with regional culture, rich subway station better and better to build a new space.

\section{References}

[1] Chen Yongchang. Interior Design, Vol. 6 (2004) No 53, p.25-26

[2] Jiang Zhuqing, Wang Qunyong. Art Design, Vol. 12 (2005) No 27, p.74-76

[3] Jiang Shuxian. Underground Space, Vol. 30 (2004) No 19, p.144-145

[4] Chen Yi. Time Architecture, Vol. 29 (2008) No 27, p.21-23

[5] Yu Meicheng, Sun Jing. Art Research, Vol. 8 (2003) No 27, p.57-60 